\title{
The Development of Emotional Regulation in Pre-Schoolers: The Role of Sociodramatic Play
}

\author{
Pilios-Dimitris Stavrou1,2 \\ ${ }^{1}$ Department of Psychology, University of Athens, Athens, Greece \\ ${ }^{2}$ Laboratory of Clinical Psychology, Psychopathology and Psychoanalysis (PCPP), University Paris Descartes, Paris, France \\ Email: stavroupd@gmail.com
}

How to cite this paper: Stavrou, P.-D. (2019). The Development of Emotional Regulation in Pre-Schoolers: The Role of Sociodramatic Play. Psychology, 10, 62-78. https://doi.org/10.4236/psych.2019.101005

Received: December 1, 2018

Accepted: January 13, 2019

Published: January 16, 2019

Copyright (c) 2019 by author(s) and Scientific Research Publishing Inc. This work is licensed under the Creative Commons Attribution International License (CC BY 4.0).

http://creativecommons.org/licenses/by/4.0/

\begin{abstract}
The present research focuses on the link between emotion regulation in preschoolers and the efficiency of sociodramatic play as a means of developing emotional and social skills appropriate for each developmental stage. In particular, we examined the effects of sociodramatic play on a four-year-old boy named Andreas, who demonstrated signs of limited emotional regulation, such as angry outbursts, inability to control his emotions and inability to cope in emotion-inducing situations. This swift in his behaviour, caused by his mother's negative control behaviour, was measured through the Emotion Regulation Checklist, the Delay Gratification Task and the Task of Effortful Control. Drawing from a plethora of theorists who support the benefits of sociodramatic play for the development of emotion regulation skills, we designed a three months school based intervention for Andreas and employed the tests beforehand and after the end of the sociodramatic sessions to explore the efficiency of the intervention. Results are discussed in regards to relevant literature.
\end{abstract}

\section{Keywords}

Sociodramatic Play, Emotion Regulation, Pre-Schoolers, School Intervention

\section{Introduction}

\subsection{Emotion Regulation among Pre-Schoolers}

Among the crucial tasks what defines development in childhood is the attainment of emotion regulation (Grolnick, McMenamy, \& Kurowski, 2006). Starting at the age of 4 to 6 , children learn how to attune their emotion to best react to situational demands (Kopp, 1989). One of the most prominent definitions of emotion regulation has been provided by Thompson, who defines it as the "ex- 
trinsic and intrinsic processes responsible for monitoring, evaluating, and modifying emotional reactions... to accomplish one's goals" (Thompson, 1994: pp. 27-28). This definition describes emotional regulation as a process in which individuals actively regulate their emotions according to their abilities and intentions.

Emotion regulation skills are essential in the development of children's social and psychological identity (Shipman et al., 2003). Children who have mastered the aforementioned skills have the ability to monitor and change their emotional reactions according to their environmental demands (Thompson, 1994), and evaluate and control their negative emotions (Kopp, 1989). The development of emotion regulation among children is linked to competence in forming social bonds, while difficulties with emotion regulation are associated to a variety of psychological disorders (Zeman et al., 2006).

Two aspects of emotion regulatory processes are often distinguished: emotional lability and adaptive regulation (Dunsmore et al., 2013). Emotional lability refers to children's response to emotion-inducing events (Pietromonaco \& Barrett, 2009). Children who have seemingly developed high emotional lability present very quick responses to emotion-eliciting situations and these responses are usually exaggerated in comparison to the actual circumstances. Moreover, children with high emotional lability struggle to restore emotional equilibrity following extreme emotional reactions. On the other hand, adaptive regulation refers to children's ability to successfully manage the emotions that appear within any context. There is a strong negative relation between the two aspects but they are not simply opposites (Dunsmore et al., 2013).

Research on ER has shown that it is associated with different types of emotional and social functioning, such as social competence, peer acceptance (Eisenberg et al., 2002), as well as academic competence (Grolnick \& Kurowski, 1999). For example, when studying ER in preschoolers, Denham et al., (2003) concluded that emotion regulation predicted concurrent social competence. Likewise, Howse et al., (2003) studied emotion regulation and behavioral regulation of children in preschool and kindergarten, and found that preschoolers who had greater emotion regulation skills had higher achievement scores in kindergarten.

\subsection{The Development of Emotional Regulation/Factors That Influence Emotional Regulation}

Basic research on regulation has identified a number of factors that influence the development of these processes at different ages, particularly biobehavioral processes, individual differences in temperament, and interpersonal processes (i.e. modulation of emotion in one person through the activity of another) (Tobin \& Graziano, 2006).

Calkins (1994) has identified two crucial features that influence the process of developing ER skills: internal elements, such as biological reactivity and behavioral traits, and external elements such as parental caregiving styles and the 
training they provide. Temperament, representing innate individual differences in emotional, behavioral, and biological reactivity to changes in environment (Rothbart \& Bates, 1998), has been hypothesized to directly shape the display and development of ER strategies (Calkins, 2004; Fox et al., 2005).

Research also supports that the presence and support of caregivers is critical in the development of ER skills during early childhood (Kopp, 1989). Research in the field of neuropsychology has shown that ER in children is affected by a variety of factors, including child temperament, neurophysiology, and cognitive development (Eisenberg \& Morris, 2002). Even though all these features are of great importance, most researchers agree that the context of family plays the most crucial role (Morris et al., 2007). Specifically, being raised in a high-risk family (with low economic status, high family stress, or maltreatment) is found to be linked to maladaptive development in children (Ackerman et al., 2004; Bradley \& Corwyn, 2002). In contrast, a series of positive characteristics of parenting have been linked to the development of children's ER skills. To illustrate, parents' ability to express warm and caring feelings is thought to serve as model of a constructive way to self-regulate, which enhances children's active attempts to regulate emotion (Eisenberg et al., 2005). Denham et al. (1997) found that preschoolers whose parents were more expressive emotionally in regards to positive emotions tended to be more socially competent at preschool.

The relationship between parents' emotional functioning and child's ER skills is also present in the case of negative or destructive emotional functioning on behalf of the parent. For example, Calkins, Smith, Gill, and Johnson (1998) reported that negative control behavior by mothers (e.g. negative control: scolding, anger expressions, derogatory remarks, threats, no's; physical control: restricting child's movement, pulling, pushing, picking child up, hand slapping; and verbal control: directing the child's activity, telling the child what to do) was associated to poor child emotional regulation, less adaptive emotional regulation, and noncompliant behavior. It appears that the impact of early infant-mother relationship shapes children's emotional response style (Bornstein \& Suess, 2000).

Indeed, the significance of the relationship with a primary parental figure in developing emotion regulation skills is evident as early as infancy. Walden and Baxter (1989) found that older infants demonstrated regulation through social referencing of a parent. Yet another study found that securely attached infants demonstrated greater parent-oriented regulation relative to infants who were less securely attached to one or both parents (Diener et al., 2002). Based on a sample of 223 children, Vondra et al., (2001) concluded that attachment classification, though not always stable between infancy and preschool, provides the most valuable information about child functioning. The influence of both temperament and relationship with caregivers continues to be important as predictors of functioning throughout early childhood.

\subsection{Sociodramatic Play and Its Link to Emotional Regulation}

Sociodramatic play is defined as an advanced form of symbolic play in which 
groups of children participate in cooperative dramatizations centered about a commonly accepted theme. As defined by Thorp, Stahmer, and Schreibman (1995), "fully developed sociodramatic play contains five elements: 1) role playing, such as pretending to be a fireman, 2) makebelieve transformations, such as pretending a block is a telephone, 3) social interaction, 4) verbal communication, and 5) persistence, or the ability to carry out a play theme from beginning to end". Clearly, children who engage in sociodramatic play should have developed an understanding of social roles and the function of social events in order to successfully create and act out make-believe scenarios (Forys \& McCune-Nicolich, 1984). Research in sociodramatic play suggests that sociodramatic play usually emerges in the third or early fourth year of life (Fein, 1981; Forys \& McCune-Nicolich, 1984).

The outcomes of sociodramatic play among children are of great significance for their cognitive and emotional development. Various studies have reported such results after teaching sociodramatic play to neurotypical children (Rosen, 1974; Saltz, Dixon, \& Johnson, 1977). Planned interventions in children's play based on the principles of sociodramatic play seem to be correlated to the increase of IQ scores (Saltz et al., 1977), problem-solving skills (Rosen, 1974), perspective-taking skills (Burns \& Brainerd, 1979), language skills (Lovinger, 1974), and social skills (Rosen, 1974; Smith, Dalgleish, \& Herzmark, 1981).

Not surprisingly, sociodramatic play has been found to relate to self-regulation in preschool children. Vygotsky (1976) was among the first to notice the importance of sociodramatic play for children's development. Indeed, he explained, "Play continually creates demands on the child to act against immediate impulse" and therefore, "A child's greatest self-control occurs in play" (p. 99). Vygotsky wasn't the only theorist to point to this connection; Bruner (1972), Garvey (1990), Russ (1995), Singer \& Singer (1990) and Smilansky (1968) were all involved in the research on the link between sociodramatic play and self-regulation. As children play, they seem to organize stimuli into schemas that facilitate their understanding of social norms. According to the aforementioned researchers, this self-regulatory function is characterized by two features that differentiate typical make believe play from other common activities; an imaginary situation and rules that are central in make believe scenarios.

Another researcher who studied extensively the link between sociodramatic play and self regulatory skills was Russ (2004), who supported that sociodramatic play provides a context for preschool children that allows them to develop and extend self-regulation skills and readiness for kindergarten. Also, during sociodramatic play, it is important for a child to control his or her impulses and emotions while taking on a specific role, attend to the role, stay on task within that role, and communicate and cooperate with his or her peers (Russ, 2004).

\subsection{The Therapist, the Make Believe Play and the Development of Emotional Regulation}

During the process of playing, adults who join children in playing can be helpful 
in many different ways, through teaching, facilitating emotional expression, and sharing positive experiences (Berk, 2001). Through this interaction therapists can encourage prosocial behaviour among children; for example, if a child is playing with a doll and pretending that the doll is hurt by someone else, the play therapist can use another doll to express empathy towards the child's doll. That way, the child's development of prosocial behaviour and competence are facilitated, which promotes the development of self-regulation (Berk et al., 2006). Indeed, research in the field shows that make believe play contributes to children developing self-regulation, which in turn allows them to use problem focused mechanisms when faced with an emotionally arousing situation (Eisenberg \& Fabes, 1992). Indeed, it is illustrated in existing literature that make believe play can lead to conflict among children, as they attempt to represent situations that experience at home or in their immediate environment; for example, a child that experiences domestic abuse will likely reproduce that through make believe playing if given a dollhouse. Therefore, make believe play allows for emotional expression and emotion management by providing children objects related to a stressor and setting a stage for children to cope on an imaginary level (Clark, 2007).

\section{Case Presentation}

Andreas is a 4 year old boy growing up in a single parent family. He attended preschool at the age of 3, at a local public preschool. His teacher explained that he was presenting difficulties in dealing with negative feelings and aggression. These patterns had manifested recently, as the previous year Andreas' behaviour was different; he did not present any signs of aggression, he interacted with other children in a very friendly and peaceful way and he seemed to have better control over his emotions. When exploring his background, we found out that he lived with his mother who worked hard to provide for both of them. According to her, him and her are very close. Nonetheless, his mother confessed that the previous year she had lost her job; since she was the sole provider in their household and Andreas' father was not supporting them financially or any other way, this posed a threat to their survival. The stress this caused Andreas' mother made her impatient and more anxious towards him than normal, resulting in tension at home. She said that she noticed changes in Andreas' behaviour shortly after she lost her job, but could respond to that sufficiently as she was struggling to find a job. The teacher placed Andreas' change in behaviour shortly after his mother lost her job. According to her, he stopped sharing toys during play hours, he would quickly become agitated if he couldn't find the toy he wanted to play with, and if another child would not be accepting of his ways or did not wish to play with him, he would resort to yelling and even hitting them. Given these behaviours that were manifested after a drastic change took place at home, Andreas was an ideal candidate to explore the benefits of sociodramatic play on the development of emotional regulation. 


\subsection{Methods}

\section{Questionnaire methods}

Emotion regulation checklist (ERC; Shields \& Cicchetti, 1997)

The ERC is a hetero-evaluation (answered by parents and/or teachers) and is a self-report that measures emotion regulation. It assesses children's ability to successfully cope with emotional experiences using a 24-item, 4 point Likert Scale ( 1 = Never, 4 = Always). This questionnaire contains two scales; adaptive emotion regulation, which targets situational appropriateness of positive emotions such as display of affection, empathy and self-awareness, and negative emotions and inability to manage them, such as mood lability and dysregulated negative affect. Samples items for the questionnaire include "Higher scores on the first scale indicated more adaptive regulatory processes whereas higher scores on the second scale indicated greater emotion dysregulation".

\section{Observational methods}

\section{Delay of gratification task}

Another way to measure emotion regulation among preschoolers is through observation. A very popular method among psychologists which measures emotion regulation using observation is the use of delay gratification tasks (Mischel \& Baker, 1995; Mischel \& Ebbesen, 1970). These tasks allow for researchers to observe and record children's ability to delay gratification when asked to wait to receive a desirable object. Additionally, this test measures the regulation methods preschoolers employ to delay gratification; there are plenty ways for a child to distract themselves in order to receive a reward, and the ones they use in each case is indicative of the way they adapt to their environment and react to the social demands posed to them (McIntyre et al., 2006; Metcalfe \& Mischel, 1999).

In this research paper we have used the most recognisable delay gratification task, namely the "marshmallow test", which was first conducted by Mischel et al at Stanford University (Mischel et al., 1972).

The experiment begins by entering a room with the child, asking them to sit down in a chair in front of an empty table and placing a marshmallow on the table. When the child is seated, the researcher informs the child of its options; they (the researcher) will leave the room and the child will be left alone with the marshmallow. If the child restrains themselves from eating the marshmallow until the researcher returns, they will receive a second marshmallow as a reward. If they eat the marshmallow before the researcher returns though, they will not get a second one. Thus, one treat is available now, but a second one requires waiting. To get the second one, the child must resist the temptation to get an immediate treat. The researcher then will leave the room for 15 minutes. This experiment allows for a demonstration of the ability to delay gratification and of different strategies that make it possible for children to delay gratification.

Andreas was placed in a separate room and was sat at able. He was presented with a marshmallow and informed that he could either consume the marshmallow now, or wait 15 minutes and receive two marshmallows instead. 
The psychologist then left the room, leaving Andreas sitting at the table. There was a video camera recording his reactions as he waited alone for 15 minutes. The observations of this task are presented in the results section.

\subsection{Task of Effortful Control}

In addition, another task that was used was the task of effortful control (EC). Developed by Kochanska and colleagues (Kochanska, Coy, \& Murray, 2001; Kochanska \& Knaack, 2003) it is a series of activities that measure a child's ability to deliberately exert control over their behaviour and emotion. In detail, EC is defined as "the capacity to deliberately suppress a dominant response and perform a subdominant response, rapidly developing in toddler and preschool age, [which] has been shown to be a robust predictor of children's adjustment" (Kim et al., 2013). Clearly, there is evidence that EC is related to self-regulation, and the different measures of EC that have been developed typically focus on attentional regulation and behavioural regulation, such as inhibitory control (Kim et al., 2013). In our research we used the task of effortful control following the task of delayed gratification, in order to obtain as many information as possible regarding Andreas' level of emotion regulation.

Specifically, we left Andreas alone in a room and placed a candy bar on a table, informing him that he would be left alone in the room, without specifying the amount of time this would last for, and instructing him not to consume the candy bar. Twenty minutes later the psychologist re-entered the room and checked whether Andreas had consumed the bar or not. Again, a video camera recorded his reactions in the time he was alone in the room and the observations are evaluated in the results section.

\subsection{Observations of Reactions to Negative Emotion}

In order to critically evaluate Andreas' management of negative emotions and the coping mechanisms he is employing in real-life contexts, we observed him for a three months period at school. In particular, we monitored his behaviour during free-play and snack periods for a total of fifteen minutes from a distance and made notes.

When Andreas was expressing negative emotions, we wrote down his specific emotional reaction and the event or situation that caused it (e.g. "Maria took his Legos to play with and he seemed upset, as he started yelling at her in a high-pitched voice, asking for his Legos back"), and what he did after expressing that emotion (e.g. "Andreas asked the teacher to intervene"). Andreas's reactions when displaying negative emotion were coded/interpreted into the following categories based on the work of Eisenberg et al., 1994; 1) verbal objection 2) venting 3) defending 4) physical retaliation-nondefensive aggression directed at either the instigator of the child's anger or another child.

\subsection{Design of Sociodramatic Play}

We designed the structure of sociodramatic play in a way that would target be- 
haviours concerning emotion regulation; we used a playroom at school that was not being used by anyone else at the time and structured an art area, a kitchen area, and a play-with-toys area.

Working for three months on a weekly basis, in 10-minute sessions, we used imitation as a way to develop Andreas' emotional regulatory behavioral patterns. We presented him with a dollhouse and co-designed activities in which we modeled how to behaviors and emotions. Furthermore, we used other methods, such as substituting language for actions. We explored Andreas' thoughts and described his behaviors to scaffold his development of self-regulation. By modeling and describing new ways of behaving, we were able to target areas of self-regulation, including self-control, attentional control, and delay of gratification.

To target emotion regulation, we used a Lego structure and child figurines. To facilitate his development of emotion regulation, the play therapist used make-believe situations that drew on his imagination to assist in the teaching of appropriate social behaviors. In this case, we used a figure that resembled Andreas, other figures that resembled his classmates, and small toys such as a toy computer or toy basketball.

Within the play setting, the figures played out social situations such as sharing toys and joining in activities. The therapist's role was to model appropriate prosocial behaviors such as sharing, compromising, and communicating with peers and adults. The therapist also elicited Andreas' imitation and practice of prosocial behaviors. Once he developed social awareness and knowledge, the play therapist moved from make-believe play to the use of sociodramatic play to assist Andreas. Thus, at least two other children joined Andreas in communicating and playing with one another. In this case, Andreas practiced these prosocial behaviors with same age peers either in the play therapy setting or in his classroom.

\section{Results}

To determine the efficiency of the intervention for Andreas' emotional regulatory skills, we used the tests mentioned above once before the sociodramatic play took place and once after the sociodramatic play sessions were over. In order to compare and contrast the change that took place in Andreas, we present below the results of both phases.

\subsection{First Phase (See Appendix)}

Emotion regulation checklist (ERC; Shields \& Cicchetti, 1997)

In the Emotion Regulation Checklist Andreas' total score was 53/96. His score at the adaptive behavior scale was $26 / 40$ and at the lability/negativity scale $27 / 56$. The results exhibit that Andrea's experiences intense mood swings. He seemed to move quickly from a positive to a negative mood. It's difficult for him to transition well from one activity to another and he often becomes angry, anxious or overly excited.

The results suggest that Andreas experiences difficulties in recovering quickly 
from distress. He is often frustrated and prone to angry outbursts. The results of the scale also show that it's hard for him to delay gratification as well as to modulate excitement. He cannot control his excitement and his is overly excited in inappropriate contexts. He also doesn't accept limits and he is very often impulsive. Additionally, he is not very often empathetic towards others. He sometimes displays negative emotions when attempting to engage others in play.

Thus, it's difficult for Andrea to modulate excitement in emotionally arousing situations, to demonstrate empathy and emotional awareness. We observe a lack of flexibility, dysregulated negative affect and inappropriate affective displays.

\section{Gratification task}

During the gratification task, Andreas gobbled the marshmallow immediately (few seconds after we left the room). When we entered at the room he told us that he loves marshmallows and that he preferred to take it immediately. As we observed in the camera, when he ate the marshmallow he began to play with the chair.

\section{Task of effortful control}

Andreas began to play with some toys he found in the room. 5 minutes later he approached the table where the candy was and he took it. He looked at the candy and he ate half of it.

\section{Observations of reactions to negative emotion}

We observed Andreas' aggressive behavior towards other children when something angers him. During the time we observed him, he directed aggressive behavior towards other children [e.g. lashing out physically, chasing another child off]. He gets angry when other children don't follow his instructions and he becomes aggressive towards them. When another child doesn't agree with him he cannot control his feelings and his embarrassment.

\subsection{Second Phase (See Appendix)}

Overall, the results of the measuring scales and the observations that were made after the end of the sociodramatic play sessions, are indicative of progress Andreas made through this three month period. These results are discussed in detail below.

\section{Emotion regulation checklist (ERC; Shields \& Cicchetti, 1997)}

During this phase, Andrea's total score in the Emotion Regulation Checklist was different to the one of the first phase. In particular, his score this time was (73/96). His score at the adaptive behavior scale was 35/40. The results demonstrate that Andreas exhibits fewer mood swings. It's easier than before for him to transition well from one activity to another. He becomes less angry, anxious or excited when moving from one activity to another. It's possible for him to delay gratification as well as to modulate excitement. He can control his excitement easier now and his is less excited in inappropriate contexts. He is not as impulsive as he used to be, and his levels of empathy towards others have raised. Nevertheless, he still occasionally displays negative emotions when attempting to 
engage with others.

\section{Gratification task}

This time, Andreas didn't gobble the marshmallow. He managed to wait 15 minutes and receive the reward of a second marshmallow. He tried to look away and he wiggled and bounced and scooted in his chairs.

\section{Task of effortful control}

Andreas began to play with some toys he found in the room. 10 minutes later he approached the table where the candy was and he took it. He didn't touch it and he continued to play with the toys he found until we entered the room.

\section{Observations of reactions to negative emotion}

We observed that Andreas' behavior towards others had changed. He rarely showed physical aggressive behavior towards other children when he is angry and disagrees with them. He continues to get angry when the other children don't follow his instructions but he doesn't become aggressive towards them. $\mathrm{He}$ can control more easily his dissatisfaction.

\section{Discussion}

In the present article we explored the process of an intervention based on sociodramatic play for a 4 year old child, Andreas, who had experienced negative control behaviour by his mother. Following the aforementioned behaviour from his mother, Andreas went through some behavioural changes that were indicative of limited emotion regulation. Granting his mother's and his teacher's coordination, we designed a school based intervention, following the principles of sociodramatic play, in order to allow him to re-establish his emotional regulation skills.

Indeed, there is a plethora of theories that link emotion regulation in children and sociodramatic play, starting from Vygotsky, who was among the first developmental psychologists who pointed towards the benefits of sociodramatic play for emotional, cognitive and behavioural development in children. According to many theorists, the use of language, imitation and pretend play that take place in sociodramatic play are of great significance for the development of children's social and emotional skills, especially in cases when children lack in emotional or behavioural competency. Specifically, two aspects of emotional regulation are deemed as critical for children's well-being and social development; emotional lability and adaptive regulation (Dunsmore et al., 2013). The term emotional lability concerns children's reaction to emotional events (Pietromonaco \& Barrett, 2009), whereas the term adaptive regulation is in reference to children's efficient management of feelings that manifest within any context (Dunsmore et al., 2013).

In order to examine the connection between the aforementioned aspects of emotion regulation in preschoolers and the effects of sociodramatic play, we worked with Andreas' teacher in the school context. We set up a sociodramatic play room where Andreas was monitored for a period of three months, and we 
measured his emotional competency before the sociodramatic play sessions began and after they were over. The results were in line with the relevant literature and are indicative of the significance of sociodramatic play as a means of promoting children's emotional development; Andreas demonstrated a critical progress within this time period in terms of emotional lability and adaptive regulation. Further research could potentially draw from this paper and explore other aspects of self-regulation in relation to sociodramatic play.

\section{Conclusion}

In conclusion, it can be assumed that the present case study has been successful in employing sociodramatic play as a means of promoting emotional regulation for a kindergarten boy named Andreas, who had previously experienced dramatic changes in his emotional stability due to his mother's inconsistent behavioural patterns in the household. This change obviously affected him, which was confirmed by his kindergarten teacher. The intervention we planned was a therapeutic approach that incorporated the benefits of consistent sociodramatic play sessions, and targeted emotion regulation skills using a plethora of tests, namely the gratification task, the task of effortful control, and the emotion regulation checklist. The results indeed showed that sociodramatic play had a critical effect on Andreas' emotion and regulation skills, and they were in line with relevant literature.

\section{Conflicts of Interest}

The author declares no conflicts of interest regarding the publication of this paper.

\section{References}

Ackerman, B. P., Brown, E. D., \& Izard, C. E. (2004). The Relations between Contextual Risk, Earned Income, and the School Adjustment of Children from Economically Disadvantaged Families. Developmental Psychology, 40, 204-216. https://doi.org/10.1037/0012-1649.40.2.204

Berk, L. E. (2001). Awakening Children's Minds: How Parents and Teachers Can Make a Difference. New York: Oxford University Press.

Berk, L. E., Mann, T. D., \& Ogan, A. T. (2006). Make-Believe Play: Wellspring for the Development of Self-Tegulation. In D. G. Singer, R. Golinkoff, \& K. Hirsh-Pasek (Eds.), Play = Learning: How Play Motivates and Enhances Children's Cognitive and Social-Emotional Growth (pp. 74-100). New York: Oxford University Press. https://doi.org/10.1093/acprof:oso/9780195304381.003.0005

Bornstein, M. H., \& Seuss, P. E. (2000). Child and Mother Cardiac Vagal Tone: Continuity, Stability, and Concordance across the First 5 Years. Developmental Psychology, 36, 54-65. https://doi.org/10.1037/0012-1649.36.1.54

Bradley, R. H., \& Corwyn, R. F. (2002). Socioeconomic Status and Child Development. Annual Review of Psychology, 53, 371-399. https://doi.org/10.1146/annurev.psych.53.100901.135233

Bruner, J. (1972). The Nature and Uses of Immaturity. American Psychologist, 27, 
687-708. https://doi.org/10.1037/h0033144

Burns, S. M., \& Brainerd, C. J. (1979). Effects on Constructive and Dramatic Play on Perspective Taking in Very Young Children. Developmental Psychology, 15, 512-421. https://doi.org/10.1037/0012-1649.15.5.512

Calkins, S. D. (1994). Origins and Outcomes of Individual Differences in Emotion Regulation. Monographs of the Society for Research in Child Development, 59, 53-72. https://doi.org/10.2307/1166138

Calkins, S. D. (2004). Temperament and Emotional Regulation: Multiple Models of Early Development. Advances in Consciousness Research, 54, 35-60. https://doi.org/10.1075/aicr.54.04cal

Calkins, S. D., Smith, C. L., Gill, K. L., \& Johnson, M. C. (1998). Maternal Interactive Style across Contexts: Relations to Emotional, Behavioral, and Physiological Regulation during Toddlerhood. Social Development, 7, 350-369. https://doi.org/10.1111/1467-9507.00072

Clark, C. D. (2007). Therapeutic Advantages of Play. In A. Goncii, \& S. Gaskins (Eds.), Play and Development: Evolutionary, Sociocultural, and Functional Perspectives (pp. 275-293). Mahwah, NJ: Erlbaum.

Denham, S. A., Blair, K. A., DeMulder, E., Levitas, J., Sawyer, K., Auerbach-Major, S., \& Queenan, P. (2003). Preschool Emotional Competence: Pathway to Social Competence? Child Development, 74, 238-256. https://doi.org/10.1111/1467-8624.00533

Denham, S. A., Mitchell-Copeland, J., Strandberg, K., Auerbach, S., \& Blair, K. (1997). Parental Contributions to Preschoolers' Emotional Competence: Direct and Indirect Effects. Motivation and Emotion, 21, 65-86. https://doi.org/10.1023/A:1024426431247

Diener, M. L., Mengelsdorf, S. C., McHale, J. L., \& Frosch, C. A. (2002). Infants' Behavioral Strategies for Emotion Regulation with Fathers and Mothers: Associations with Emotional Expressions and Attachment Quality. Infancy, 3, 153-174. https://doi.org/10.1207/S15327078IN0302_3

Dunsmore, J. C., Booker, J. A., \& Ollendick, T. H. (2013). Parental Emotion Coaching and Child Emotion Regulation as Protective Factors for Children with Oppositional Defiant Disorder. Social Development, 22, 444-466. https://doi.org/10.1111/j.1467-9507.2011.00652.x

Eisenberg, N., \& Fabes, R. A. (1992). Emotion, Regulation, and the Development of Social Competence. In M. S. Clark (Ed.), Review of Personality and Social Psychobgy: Vol. 14. Emotion and Behavior (pp. 119-150). Newbury Park, CA: Sage.

Eisenberg, N., \& Morris, A. S. (2002). Children's Emotion-Related Regulation. Advances in Child Development and Behavior, 30, 189-229. https://doi.org/10.1016/S0065-2407(02)80042-8

Eisenberg, N., Fabes, R. A., Guthrie, I. K., \& Reiser, M. (2002). The Role of Emotionality and Regulation in Children's Social Competence and Adjustment. In L. Pulkinnen, \& A. Caspi (Eds.), Paths to Successful Development: Personality in the Life Course (pp. 46-70). Cambridge: Cambridge University Press. https://doi.org/10.1017/CBO9780511489761.003

Eisenberg, N., Fabes, R. A., Minore, D., Mathy, R., Hanish, L., \& Brown, T. (1994). Children's Enacted Interpersonal Strategies: Their Relations to Social Behavior and Negative Emotionality. Merrill-Palmer Quarterly, 212-232.

Eisenberg, N., Zhou, Q., Spinrad, T. L., Valiente, C., Fabes, R. A., \& Liew, J. (2005). Relations among Positive Parenting, Children's Effortful Control, and Externalizing Problems: A Three-Wave Longitudinal Study. Child Development, 76, 1055-1071. 
https://doi.org/10.1111/j.1467-8624.2005.00897.x

Fein, G. G. (1981). Pretend Play in Childhood: An Integrative Review. Child Development, 52, 1095-1118. https://doi.org/10.2307/1129497

Forys, S., \& McCune-Nicholich, L. (1984). Shared Pretend: Sociodramatic Play at 3 Years of Age. In I. Bretherton (Ed.), Symbolic Play: The Development of Social Understanding (pp. 159-191). New York: Academic Press.

Fox, N. A., Henderson, H. A., Marshall, P. J., Nichols, K. E., \& Ghera, M. M. (2005). Behavioral Inhibition: Linking Biology and Behavior within a Developmental Framework. Annual Review of Psychology, 56, 235-262. https://doi.org/10.1146/annurev.psych.55.090902.141532

Garvey, C. (1990). Play. Cambridge, MA: Harvard University Press.

Grolnick, W. S., \& Kurowski, C. O. (1999). Family Processes and the Development of Children's Self-Regulation. Educational Psychologist, 34, 3-14. https://doi.org/10.1207/s15326985ep3401_1

Grolnick, W. S., McMenamy, J. M., \& Kurowski, C. O. (2006). Emotional Self-Regulation in Infancy and Toddlerhood. In L. Balter, \& C. S. Tamis-LeMonda (Eds.), Child Psychology: A Handbook of Contemporary Issues (2nd ed., pp. 3-25). New York: Psychology Press.

Howse, R. B., Calkins, S. D., Anastopoulos, A. D., Keane, S. P., \& Shelton, T. L. (2003). Regulatory Contributors to Children's Kindergarten Achievement. Early Education and Development, 14, 101-120. https://doi.org/10.1207/s15566935eed1401_7

Kim, S., Nordling, J. K., Yoon, J. E., Boldt, L. J., \& Kochanska, G. (2013). Effortful Control in "Hot" and "Cool” Tasks Differentially Predicts Children's Behavior Problems and Academic Performance. Journal of Abnormal Child Psychology, 41, 43-56. https://doi.org/10.1007/s10802-012-9661-4

Kochanska, G., \& Knaack, A. (2003). Effortful Control as a Personality Characteristic of Young Children: Antecedents, Correlates, and Consequences. Journal of personality, 71, 1087-1112. https://doi.org/10.1111/1467-6494.7106008

Kochanska, G., Coy, K. C., \& Murray, K. T. (2001). The Development of Self-Regulation in the First Four Years of Life. Child Development, 72, 1091-1111. https://doi.org/10.1111/1467-8624.00336

Kopp, C. B. (1989). Regulation of Distress and Negative Emotions: A Developmental View. Developmental Psychology, 25, 343-354. https://doi.org/10.1037/0012-1649.25.3.343

Lovinger, S. L. (1974). Sociodramalic Play and Language Development in Preschool Disadvantaged Children. Psychology in Schools, 11, 313-320. https://doi.org/10.1002/1520-6807(197407)11:3<313::AID-PITS2310110315>3.0.CO;2-L

McIntyre, L. L., Blacher, J., \& Baker, B. L. (2006). Transition to School: Adaptation in Young Children with and without Developmental Delays. Journal of Intellectual Disability Research, 50, 349-361. https://doi.org/10.1111/j.1365-2788.2006.00783.x

Metcalfe, J., \& Mischel, W. (1999). A Hot-Cool System Analysis of Delay of Gratification: Dynamics of Willpower. Psychological Review, 106, 3-19. https://doi.org/10.1037/0033-295X.106.1.3

Mischel, W., \& Baker, N. (1995). Cognitive Appraisals and Transformations in Delay Behavior. Journal of Personality and Social Psychology, 31, 254-261.

Mischel, W., \& Ebbesen, E. B. (1970). Attention in Delay of Gratification. Journal of Personality and Social Psychology, 16, 329-337. https://doi.org/10.1037/h0029815

Mischel, W., Ebbesen, E. B., \& Raskoff Zeiss, A. (1972). Cognitive and Attentional 
Mechanisms in Delay of Gratification. Journal of Personality and Social Psychology, 21, 204-218. https://doi.org/10.1037/h0032198

Morris, A. S., Silk, J. S., Steinberg, L., Myers, S. S., \& Robinson, L. R. (2007). The Role of the Family Context in the Development of Emotion Regulation. Social Development, 16, 361-388. https://doi.org/10.1111/j.1467-9507.2007.00389.x

Pietromonaco, P. R., \& Barrett, L. F. (2009). Valence Focus and Self-Esteem Lability: Reacting to Hedonic Cues in the Social Environment. Emotion, 9, 406-418. https://doi.org/10.1037/a0015691

Rosen, C. E. (1974). The Effects of Sociodramalic Play on Problem Solving-Behavior among Culturally Disadvantaged Preschool Children. Child Development, 45, 920-927. https://doi.org/10.2307/1128077

Rothbart, M. K., \& Bates, J. E. (1998). Temperament. In N. Eisenberg (Ed.), Handbook of Child Psychology: Vol. 3. Social, Emotional, and Personality Development (pp. 105-176). New York: Wiley.

Russ, S. W. (1995). Play Psychotherapy Research: State of the Science. In T. H. Ollendick, \& R. J. Prinz (Eds.), Advances in Clinical Psychology (Vol. 17, pp. 365-391). New York: Plenum.

Russ, S. W. (2004). Play in Child Development and Psychotherapy: Toward Empirically Supported Practice. Mahwah, NJ: Lawrence Erlbaum Associates.

Saltz, E., Dixon, D., \& Johnson, J. (1977). Training Disadvantaged Preschoolers on Various Fantasy Activities: Effects on Cognitive Functioning and Impulse Control. Child Development, 48, 367-380. https://doi.org/10.2307/1128629

Shields, A., \& Cicchetti, D. (1997). Emotion Regulation among School-Age Children: The Development and Validation of a New Criterion Q-Sort Scale. Developmental Psychology, 33, 906. https://doi.org/10.1037/0012-1649.33.6.906

Shipman, K., Zeman, J., Fitzgerald, M., \& Swisher, L. M. (2003). Regulating Emotion in Parent-Child and Peer Relationships: A Comparison of Sexually Maltreated and Nonmaltreated Girls. Child Maltreatment, 8, 163-172.

https://doi.org/10.1177/1077559503254144

Singer, D. G., \& Singer, J. L. (1990). The House of Make-Believe. Cambridge, MA: Harvard University Press.

Smilansky, S. (1968). The Effects of Sociodramatic Play on Disadvantaged Children. New York: Wiley.

Smith, P. K., Dalgleish, M., \& Herzmark, G. (1981). A Comparison of the Effects of Fantasy Lay Tutoring and Skills Tutoring in Nursery Classes. International Journal of Behavioral Development, 4, 421-441.

Thompson, R. A. (1994). Emotion Regulation: A Theme in Search of Definition. Monographs of the Society for Research in Child Development, 59, 25-52. https://doi.org/10.2307/1166137

Thorp, D. M., Stahmer, A. C., \& Schreibman, L. (1995). Effects of Sociodramatic Play Training on Children with Autism. Journal of Autism and Developmental Disorders, 25, 265-282. https://doi.org/10.1007/BF02179288

Tobin, R. M., \& Graziano, W. G. (2006). Development of Regulatory Processes through Adolescence: A Review of Recent Empirical Studies. In D. Mroczek, \& T. Little (Eds.), Handbook of Personality Development (pp. 263-283). Mahwah, NJ: Erlbaum.

Vondra, J. I., Shaw, D. S., Swearingen, L., Cohen, M., \& Owens, E. B. (2001). Attachment Stability and Emotional and Behavioral Regulation from Infancy to Preschool Age. 
Development \& Psychopathology, 13, 13-33.

https://doi.org/10.1017/S095457940100102X

Vygotsky, L. S. (1976). Play and Its Role in the Mental Development of the Child. In J. S. Bruner, A. Jolly, \& K. Sylva (Eds.), Play-Its Role in Development and Evolution (pp. 537-554). New York, NY: Basic Books.

Walden, T. A., \& Baxter, A. (1989). The Effect of Context and Age on Social Referencing. Child Development, 60, 1511-1518. https://doi.org/10.2307/1130939

Zeman, J., Cassano, M., Perry-Parrish, C., \& Stegall, S. (2006). Emotion Regulation in Children and Adolescents. Journal of Developmental \& Behavioral Pediatrics, 27, 155-168. https://doi.org/10.1097/00004703-200604000-00014 


\section{Appendix}

\section{FIRST PHASE}

\begin{tabular}{|c|c|c|c|c|}
\hline & & $\mathrm{L} / \mathrm{N}$ & $\mathrm{RE}$ & RE Total \\
\hline Item & Score & & 3 & 3 \\
\hline 1 & 3 & (Inv) 2 & & (Inv) 2 \\
\hline 2 & 3 & & 4 & 4 \\
\hline 3 & 4 & & 2 & 2 \\
\hline 4 & 2 & & 1 & 1 \\
\hline 5 & 1 & (Inv) 2 & & (Inv) 2 \\
\hline 6 & 3 & & 3 & 3 \\
\hline 7 & 3 & (Inv) 2 & & (Inv) 2 \\
\hline 8 & 3 & 1 & & 1 \\
\hline 9 & 1 & (Inv) 2 & & (Inv) 2 \\
\hline 10 & 3 & 1 & & 1 \\
\hline 11 & 1 & (Inv) 2 & & (Inv) 2 \\
\hline 12 & 3 & (Inv) 1 & & (Inv) 1 \\
\hline 13 & 4 & (Inv) 2 & & (Inv) 2 \\
\hline 14 & 3 & & 2 & 2 \\
\hline 15 & 2 & & (Inv) 3 & (Inv) 3 \\
\hline 16 & 2 & (Inv) 2 & & $(\operatorname{Inv}) 1$ \\
\hline 17 & 4 & & (Inv) 3 & (Inv) 3 \\
\hline 18 & 2 & & (Inv) 3 & (Inv) 3 \\
\hline 19 & 2 & (Inv) 2 & & (Inv) 2 \\
\hline 20 & 3 & & 2 & 2 \\
\hline 21 & 2 & (Inv) 2 & & (Inv) 1 \\
\hline 22 & 4 & 3 & & 3 \\
\hline 23 & 3 & (Inv) 3 & & (Inv) 3 \\
\hline 24 & 2 & $\Sigma=27$ & $\Sigma=26$ & $\Sigma=53$ \\
\hline
\end{tabular}

Emotion regulation checklist (ERC; Shields \& Cicchetti, 1997) 


\section{SECOND PHASE}

\begin{tabular}{|c|c|c|c|c|}
\hline & & $\mathrm{L} / \mathrm{N}$ & $\mathrm{RE}$ & RE Total \\
\hline Item & Score & & 3 & 3 \\
\hline 1 & 3 & $(\operatorname{Inv}) 3$ & & (Inv) 3 \\
\hline 2 & 2 & & 4 & 4 \\
\hline 3 & 4 & & 3 & 3 \\
\hline 4 & 3 & & 3 & 3 \\
\hline 5 & 3 & (Inv) 3 & & (Inv) 3 \\
\hline 6 & 2 & & 4 & 4 \\
\hline 7 & 4 & (Inv) 3 & & (Inv) 3 \\
\hline 8 & 2 & 3 & & 3 \\
\hline 9 & 3 & (Inv) 3 & & (Inv) 3 \\
\hline 10 & 2 & 3 & & 3 \\
\hline 11 & 3 & (Inv) 2 & & (Inv) 2 \\
\hline 12 & 3 & (Inv) 3 & & (Inv) 3 \\
\hline 13 & 2 & (Inv) 1 & & (Inv) 1 \\
\hline 14 & 2 & & 3 & 3 \\
\hline 15 & 3 & & (Inv) 4 & (Inv) 4 \\
\hline 16 & 1 & (Inv) 2 & & (Inv) 2 \\
\hline 17 & 3 & & (Inv) 4 & (Inv) 4 \\
\hline 18 & 1 & & (Inv) 4 & (Inv) 4 \\
\hline 19 & 1 & (Inv) 3 & & (Inv) 3 \\
\hline 20 & 2 & & 3 & 3 \\
\hline 21 & 3 & (Inv) 3 & & (Inv) 3 \\
\hline 22 & 2 & 3 & & 3 \\
\hline 23 & 3 & (Inv) 3 & & (Inv) 3 \\
\hline 24 & 2 & $\Sigma=38$ & $\Sigma=35$ & $\Sigma=73$ \\
\hline
\end{tabular}

Emotion regulation checklist (ERC; Shields \& Cicchetti, 1997) 